\title{
Antiangiogenesis Therapy of Endometriosis Using PAMAM as a Gene Vector in a Noninvasive Animal Model
}

\author{
Ningning Wang, ${ }^{1}$ Bin Liu, ${ }^{1}$ Lili Liang, ${ }^{1}$ Yanxin $W u,{ }^{1}$ Hongzhe Xie, ${ }^{1}$ Jiaming Huang, \\ Xu Guo, ${ }^{1}$ Jinfeng Tan, ${ }^{1}$ Xuejun Zhan, ${ }^{1}$ Yongdong Liu, ${ }^{2}$ Liantang Wang, ${ }^{2}$ and Peiqi Ke ${ }^{1}$ \\ ${ }^{1}$ Department of Obstetrics and Gynecology, The First Affiliated Hospital of Sun Yat-sen University, \\ 58th Zhongshan 2nd Road, Guangzhou 510080, China \\ ${ }^{2}$ Department of Pathology, The First Affiliated Hospital of Sun Yat-sen University, 58th Zhongshan 2nd Road, \\ Guangzhou 510080, China \\ Correspondence should be addressed to Ningning Wang; wangnn@mail.sysu.edu.cn and Peiqi Ke; 13728002333@139.com
}

Received 27 January 2014; Revised 24 April 2014; Accepted 29 May 2014; Published 24 June 2014

Academic Editor: Giulia Montanari

Copyright (c) 2014 Ningning Wang et al. This is an open access article distributed under the Creative Commons Attribution License, which permits unrestricted use, distribution, and reproduction in any medium, provided the original work is properly cited.

\begin{abstract}
Objective. To evaluate the characteristics and antiangiogenic effects of endostatin-loaded PAMAM on endometriosis in a noninvasive animal model. Materials and Methods. A noninvasive animal model was established by injecting adenovirus-GFP transfected endometrial stromal and glandular epithelial cells subcutaneously into nude mice. Endostatin-loaded PAMAM was prepared and identified by transmission electron microscopy. For in vitro studies, the DNA protection and cytotoxicity of PAMAM were investigated and compared with Lipofectamine 2000. For in vivo study, endostatin-loaded PAMAM was injected into the noninvasive model and evaluated by continuously observing the fluorescent lesion, lesion weight, microvessel density and VEGF immunostaining. Results. Compared with Lipofectamine 2000, PAMAM and HC PAMAM-ES group, MC PAMAM-ES group and LC PAMAM-ES group demonstrated a better stromal cells protective such that MC PAMAM-ES group of CCK8 was $0.617 \pm 0.122$ at $24 \mathrm{hr}$ and $0.668 \pm 0.143$ at $48 \mathrm{hr}$ and LC PAMAM-ES group of CCK 8 was $0.499 \pm 0.103$ at $24 \mathrm{hr}$ and $0.610 \pm 0.080$ at $48 \mathrm{hr}$ in stromal cells $(P<0.05)$ but similar cytotoxicity in glandular epithelial cells in vitro. After 16 hrs of digestion, DNA decreased slightly under the protection of PAMAM. Endostatin-loaded PAMAM of HD PAMAM-ES group and LD PAMAM-ES group inhibited the growth of the endometriotic lesion in vivo at days 15,20, 25 and 30 detected by noninvasive observation after injecting one dose endostatin of various medicines into the endometrial lesion in each mouse on day $10(P<0.05)$ and confirmed by lesion weight at day 30 with HD PAMAM-ES group being $0.0104 \pm 0.0077 \mathrm{~g}$ and LD PAMAM-ES group being $0.0140 \pm 0.0097 \mathrm{~g}(P<0.05)$. Immunohistochemistry results showed that endostatin-loaded PAMAM reduced the microvessel density $3.8 \pm 2.4$ especially in HD PAMAM-ES group in the lesion $(P<0.05)$. Conclusion. Endostatin-loaded PAMAM inhibits the development of endometriosis through an antiangiogenic mechanism and can be observed through the noninvasive endometriosis model.
\end{abstract}

\section{Introduction}

Endometriosis, defined as functioning endometrium outside the uterine cavity, is a common disease in women of reproductive age. Patients suffering from endometriosis may develop chronic pelvic pain, dysmenorrhea, dyspareunia, and infertility [1]. The prevalence of endometriosis has increased in recent years, while the etiology and mechanism have not been completely understood. Previous research shows that retrograde shedding [2], adherence and ectopic implantation $[3,4]$, and angiogenesis $[5,6]$ of the endometrium are three important steps in the development of endometriosis. In these processes, angiogenesis plays an important role in the formation of endometriosis because growing ectopic lesions need rich blood supply. Therefore, antiangiogenesis therapy is an important approach in the management of endometriosis.

In previous studies, endostatin has been identified as a useful and safe inhibitor for angiogenesis [1, 7-11]. However, as a protein reagent, endostatin can only function for a short time and thus is not suitable for a recurrent disease such as endometriosis. Therefore, we presumed that, a longterm drug delivery system, transferring endostatin gene into endometriotic lesions might be a better strategy for the treatment of endometriosis. 
On the basis of our previous studies, the $20 \mu \mathrm{g}$ endostatin gene transduced by $65 \mu \mathrm{g}$ Lipofectamine 2000 inhibited the growth of endometriotic lesions with some stromal cells (ESCs) inhibited without any reproductive side effects in a nude mouse model [12]. Recently, a novel compound, polyamidoamine (PAMAM) dendrimers, has been certified as a nontoxic gene vector with high transduction efficiency [13]. However, the effect of PAMAM varied in different studies and has not been confirmed in the research on endometriosis.

To test the effect of the PAMAM-transduced endostatin gene on endometriosis, we applied the same noninvasive animal model established successfully by our research group [14]. In this model, we labeled endometrial stroma cells (ESCs) and grandular epithelial cells (EECs) separately with green fluorescence to form human endometriotic lesions by isolation-transfection-incubation procedure in nude mice and followed the fluorescent label in vivo noninvasively. This model helped us to repeatedly observe the lesion, and the application of the image analysis software helped us to study lesion changes quantitatively. At the same time, the accurate quantitative application of PAMAM and its effect are assessed in vitro and in vivo.

\section{Materials and Methods}

2.1. Endometrium Sample Collection. Samples of proliferative phase endometrium which are confirmed by histology were obtained from 16 women who received hysteroscopy for diagnostic purposes in our department between April and June 2009. All participants were aged 20-45 yrs (mean age 30), without internal complications and with regular menstrual cycles and no hormonal treatment for the last 3 months before surgery. Pieces of normal endometrium were obtained in surgery and immediately transferred into $4^{\circ} \mathrm{C}$ DMEM/F12 (Gibco, Carlsbad, CA, USA) supplemented with $1 \%$ penicillin and streptomycin (HyClone, Logan, UT, USA). An informed written consent was given by each patient before tissue collection. This protocol was approved by the First Affiliated Hospital of Sun Yat-sen University Ethical Review Committee.

2.2. Isolation and Primary Culture of ESCs and EECs. All experiments started within $1 \mathrm{hr}$ after collection of the endometrium. The isolation of endometrial cells was in accordance with the methods stated in Ryan et al. [15] with some modification. In detail, endometrial tissue was washed 3 times with PBS, transferred to DMEM/F12 (Gibco, Carlsbad, CA, USA), supplemented with $1 \%$ penicillin and streptomycin (HyClone, Logan, UT, USA), and cut into 1$2 \mathrm{~mm}^{3}$ pieces. Then, the tissue was digested with $2 \mathrm{mg} / \mathrm{mL}$ collagenase I (Gibco, Carlsbad, CA, USA) at $37^{\circ} \mathrm{C}$ in $5 \%$ $\mathrm{CO}_{2}$ for $1 \mathrm{hr}$. After digestion, a sterile $150 \mu \mathrm{m}$ polyethylene mesh filter (Shen Yue instrument store, Guangzhou, China) was used to remove undigested debris, followed by a $45 \mu \mathrm{m}$ cell strainer to separate EECs from ESCs. The EECs were backwashed with DMEM/F12 from the $45-\mu \mathrm{m}$ cell strainer (Shen Yue instrument store, Guangzhou, China) onto the dish. After being centrifuged, the ESCs and EECs were resuspended with DMEM/F12 and 10\% FCS then cultured in a 6-well plate.

2.3. Preparation and Identification of the Endostatin Plasmid Mixture. The preparation of the PAMAM-Es plasmid mixture was performed according to the Dendritech Company guidelines. Six PAMAM dendrimers were dissolved in water at a concentration of $1 \mathrm{mg} / \mathrm{mL}$ and stored at $4^{\circ} \mathrm{C}$. The human recombined endostatin plasmid was stored at $-20^{\circ} \mathrm{C}$. When used, the PAMAM solution and the endostatin plasmid were both rewarmed in room temperature on the bench for $20 \mathrm{~min}$ and mixed together at a ratio of $3.25 \mu \mathrm{g}: 1 \mu \mathrm{g}$ (PAMAM : endostation). After $20 \mathrm{~min}$ of coincubation, the mixture was identified by JEM-2010HR transmission electron microscopy (JEOL, Tokyo, Japan).

As a traditional gene vector, Lipofectamine 2000 was taken to compare with PAMAM in both in vitro and in vivo studies. The preparation of the Lipofectamine-endostatin plasmid mixture (Lipo-Es) was in accordance with the routine of our laboratory. Briefly, Lipofectamine 2000 and endostatin plasmid were rewarmed in room temperature on the bench top for $20 \mathrm{~min}$ and mixed together at a ratio of $3.25 \mu \mathrm{g}: 1 \mu \mathrm{g}$ and cultured for another $20 \mathrm{~min}$ before injection.

2.4. In Vitro Studies on the DNA-Protection Effect and Cytotoxicity of PAMAM. To determine the protection of plasmid by PAMAM, $5 \mathrm{U}$ of DNase I was added into a $50 \mu \mathrm{L}$ solution containing PAMAM-Es or Lipo-Es plasmid or naked plasmid. The primary plasmid concentration in each group was $0.200 \mathrm{mg} / \mathrm{mL}$. OD260 values were detected by biophotometer after $1,4,8$, and 16 hrs.

Cytotoxicity of PAMAM and PAMAM-Es was processed on primary cultural ESCs or EECs. Purified cells were cultured in 96-well plates with a density of 5000 cells/well for ESCs and 20 cells mass/well for EECs, respectively. Twentyfour hours after primary culture, the medium in the 96-well plates was discarded and $100 \mu \mathrm{L}$ of OptiMEM (Gibco BRL, Grand Island, NY, USA) was added into each well. Then, the PAMAM-Es mixture with various dilutions, the Lipo-Es mixture, and the PAMAM solution (shown in Table 1) were added into each group. After culturing for $24 \mathrm{hrs}, 10 \mu \mathrm{L}$ of the CCK-8 reagent was added into each well, incubated in $37^{\circ} \mathrm{C}$, $5 \% \mathrm{CO}_{2}$ for $2 \mathrm{hrs}$, and detected by a Tecan biophotometer at $495 \mathrm{~nm}$.

2.5. In Vivo Observation and Quantitative Analysis of GFPExpressing Lesions in Nude Mice. According to our preliminary work [14], the isolation-transfection-incubation mixed cells injecting subcutaneous procedure was also performed in this experiment. Forty female nude mice (BALB/c), aged 6-8 weeks and weighing 17-21g, were provided by the National Rodent Laboratory Animal Resources, Shanghai Branch (Shanghai, China). Two days before endometrial cell injection, a sterile 60 -day release pellet, containing $1.7 \mathrm{mg}$ of 17-beta E2 (Innovative Research of America, USA), was added to implant s.c. for every nude mice. 
TABLE 1: Medicines used in cytotoxicity test.

\begin{tabular}{lccc}
\hline Group & $\begin{array}{c}\text { Plasmid } \\
(\mu \mathrm{g} / \mathrm{mL})\end{array}$ & $\begin{array}{c}\text { Vector } \\
(\mu \mathrm{g} / \mathrm{mL})\end{array}$ & $\begin{array}{c}\text { Number of } \\
\text { wells }\end{array}$ \\
\hline (1) HC PAMAM-Es & 10 & 32.5 & 6 \\
(2) MC PAMAM-Es & 1 & 3.25 & 6 \\
(3) LC PAMAM-Es & 0.1 & 0.325 & 6 \\
(4) Lipofectamine-Es & 10 & 32.5 & 6 \\
(5) PAMAM & - & 32.5 & 6 \\
(6) Blank control & - & - & 6 \\
\hline
\end{tabular}

TABLE 2: Medicines used in treatment of animal model.

\begin{tabular}{lccc}
\hline Group & $\begin{array}{c}\text { Endostatin } \\
\text { plasmid }(\mu \mathrm{g})\end{array}$ & $\begin{array}{c}\text { Vector } \\
(\mu \mathrm{g})\end{array}$ & $\begin{array}{c}\text { Number of } \\
\text { mice }\end{array}$ \\
\hline (1) HD PAMAM-Es & 20 & 65 & 8 \\
(2) LD PAMAM-Es & 10 & 32.5 & 8 \\
(3) Lipofectamine-Es & 20 & 65 & 8 \\
(4) PAMAM & - & 65 & 8 \\
(5) PBS & - & $65 \mathrm{uL}$ & 8 \\
\hline
\end{tabular}

For in vivo imaging of GFP-expressing endometrial lesions, animals were put on a fluorescent stereomicroscope (SZX16, Olympus, Tokyo, Japan) equipped with a $470 \mathrm{~nm}$ filter. Images were recorded with an Olympus DP71 digital camera (Olympus, Tokyo, Japan) fixed with a $515 \mathrm{~nm}$ viewing filter. Each mouse was observed 6 times on days 5, 10, 15, 20, 25 , and 30 after cells implantation.

Quantitative analysis was completed primarily according to Fortin et al. [16]. In short, at each time point, three fluorescent images were acquired for each mouse. Image software was used to identify the number and intensity of pixels corresponding to the spectral signature of GFP (present only in regions of interesting where there is a lesion) and the size of each lesion. If more than one lesion was present on a mouse, the calculated surface is the sum of each individual lesion.

To investigate whether the fluorescent area in the imaged lesion is representative of the actual lesion size, we used a traditional method to measure the length $(a)$ and width $(b)$ of the lesion with a vernier caliper and calculated the volume of the lesion with a well-recognized formula $\left(V=(1 / 2) a \times b^{2}\right)$. Then, a correlation test was applied to study the correlation between the volume of the lesion and the fluorescent area in the photo.

2.6. Treatment of Human Recombined Endostatin Plasmid Using PAMAM as a Vector. Forty nude mice were randomly divided into 5 groups according to their weight, lesion volumes, and fluorescent pixel numbers on days 5 and 10: (1) HD PAMAM-Es group: $20 \mu \mathrm{g}$ Es/65 $\mu \mathrm{g}$ PAMAM; (2) LD PAMAM-Es group: $10 \mu \mathrm{g}$ Es/32.5 $\mu \mathrm{g}$ PAMAM; (3) Lipofectamine-Es group: $20 \mu \mathrm{Es} / 65 \mu \mathrm{g}$ Lipofectamine; (4) PAMAM group: $65 \mu \mathrm{g}$ PAMAM; (5) PBS group: same volume PBS. Each group received different treatments (shown in Table 2) by injecting one dose of various medicines into the endometrial lesion in each mouse on day 10, just after the second noninvasive observation.

Three approaches were used to evaluate the antiangiogenesis effects of PAMAM-Es. First, the variation in fluorescent areas of the lesions before and after treatment was calculated and compared among each group. Second, volume changes among the 5 groups were analyzed. Third, after 30 days of in vivo observation, mice were sacrificed and lesions in different groups were excised and weighed with an electronic balance.

2.7. Evaluation of Antiangiogenesis Efficiency of PAMAMEndostatin. After being weighed, the lesions were then fixed in $4 \%$ PFA for 24 hours at room temperature and embedded in paraffin. Sections of $5 \mu \mathrm{m}$ were first stained with hematoxylin and eosin to evaluate the lesions' viability and quality. Microvessel density (MVD) and VEGF expression of the lesion were determined by immunohistochemistry staining using horseradish peroxidase detection system (Zhongshan, Beijing, China) with polyclonal rabbit anti-CD31 antibody (dilution of 1:250, Abcam) and monoclonal rabbit antihuman VEGF antibody (dilution of 1:250, Abcam). The slides were counterstained with hematoxylin.

Two blinded observers examined the tissue with a microscope (IX71, Olympus, Tokyo, Japan). For the MVD calculations, the regions with the highest microvessel density (hot spots) were scanned at low magnification $(\times 40)$ as described by Weidner [17] and counted at a $\times 400$ magnification in a blinded fashion. For each slide, microvessels were counted twice in 5 different high magnifications and the average was used as the final value.

For VEGF analysis, slides were first scanned at low magnification $(\times 40)$, and five fields of the immunostained sections were randomly chosen for histomorphometry at $\times 400$ magnification. A semiquantitative evaluation of immunohistochemical staining for VEGF was performed according to the method described by Donnez et al. [18], involving the analysis of the distribution and the intensity of staining within the endothelium and glandular epithelium or stroma. The histologic scores $(H)$ for VEGF were calculated using the formula $H=\Sigma P_{i}$, where $i$ is the intensity ranging from 0 (negative cells) to 3 (deeply staining cells) and $P$ is the percentage of staining cells for each given $i$, with $P$ values of $1,2,3,4$, and 5 indicating $<15 \%, 15-50 \%, 50-85 \%,>85 \%$, and $100 \%$ positive-staining cells, respectively. The staining result was expressed as the mean \pm standard deviation.

2.8. Statistics. Data were analyzed by SPSS 13.0 software. For the cytotoxicity study in vitro, OD values of various treatments were described as the mean \pm SD and analyzed by one-way ANOVA. For noninvasive in vivo studies, the corelationship between fluorescent pixel numbers and the volumes of each lesion was tested. A two-way ANOVA analysis (main effect: group and time; interaction: group and time) was applied to compare lesion fluorescent pixel numbers among groups. For the invasive study, lesion weight, MVD count, and VEGF histology scores were compared among groups using one-way ANOVA. In this study, all the ANOVA tests were followed by a post hoc Bonferroni test 
TABLe 3: Cytotoxicity test of ESCs and EECs by CCK-8 Kit (absorbance, mean \pm S.D).

\begin{tabular}{lcccc}
\hline & \multicolumn{2}{c}{ Stromal cell } & \multicolumn{2}{c}{ Glandular epithelial cell } \\
& $24 \mathrm{~h}$ & $48 \mathrm{~h}$ & $24 \mathrm{~h}$ & $0.233 \pm 0.114$ \\
\hline Control & $0.625 \pm 0.155$ & $0.648 \pm 0.117$ & $0.409 \pm 0.252$ & $0.385 \pm 0.218$ \\
HC PAMAM-Es & $0.118 \pm 0.019^{\mathrm{a}}$ & $0.088 \pm 0.007^{\mathrm{a}}$ & $0.395 \pm 0.156$ & $0.325 \pm 0.060$ \\
MC PAMAM-Es & $0.617 \pm 0.122$ & $0.668 \pm 0.143$ & $0.337 \pm 0.167$ & $0.290 \pm 0.071$ \\
LC PAMAM-Es & $0.499 \pm 0.103$ & $0.610 \pm 0.080$ & $0.347 \pm 0.171$ & $0.255 \pm 0.063$ \\
Lipo-Es & $0.202 \pm 0.081^{\mathrm{a}}$ & $0.136 \pm 0.049^{\mathrm{a}}$ & $0.328 \pm 0.138$ & $0.265 \pm 0.054$ \\
PAMAM & $0.167 \pm 0.083^{\mathrm{a}}$ & $0.096 \pm 0.018^{\mathrm{a}}$ & 0.193 & 0.651 \\
$F$ & 31.444 & 71.95 & 0.963 & 0.663 \\
$P$ & 0.000 & 0.000 & &
\end{tabular}

${ }^{a}$ Statistic significant difference compared with control group.

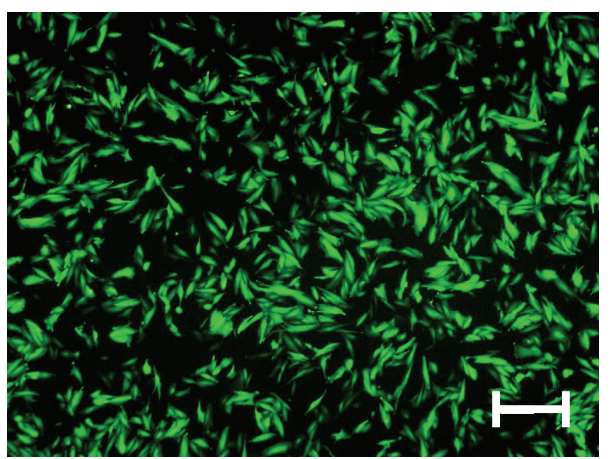

(a)

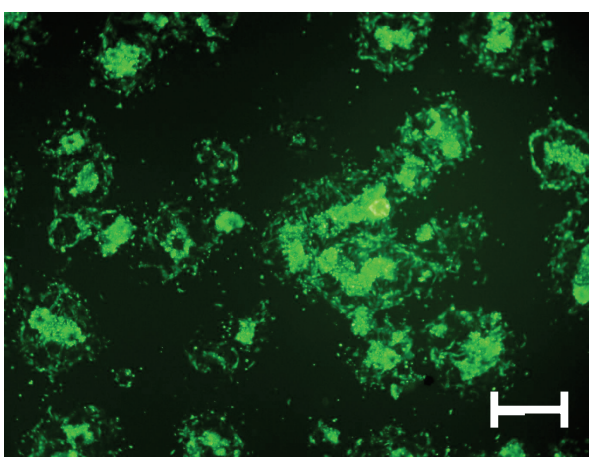

(b)

FIGURE 1: Primary cultural stromal cells (a) and glandular epithelial cell masses (b) expressed green fluorescent after adenovirus-eGFP transfection for $18 \mathrm{~h}(100 \mathrm{x}, \mathrm{Bar}=200 \mu \mathrm{m})$.

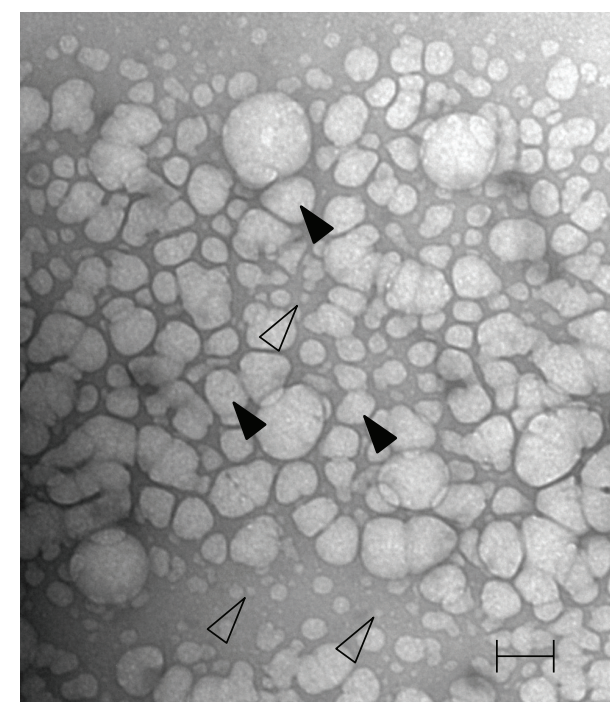

(a)

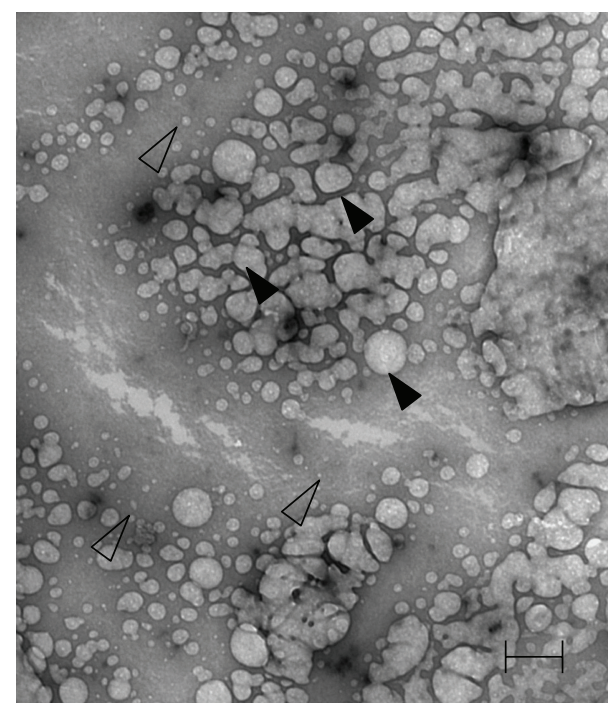

(b)

Figure 2: Structure of PAMAM and PAMAM-Es was similar under transmission electron microscopy (37000x, BAR = 200 nm). (a) Morphology of PAMAM under TEM. (b) Morphology of PAMAM-Es under transmission electron microscopy. Open arrows: PAMAM monomer (diameter: 5-10 nm); close arrows: PAMAM polymerize compound (diameter: 50-200 nm). 
TABLE 4: Area of fluorescent lesion in treatment and control groups at different time point (pixel).

\begin{tabular}{|c|c|c|c|c|c|c|}
\hline Group & Day 5 & Day 10 & Day 15 & Day 20 & Day 25 & Day 30 \\
\hline (1) HD PAMAM-Es ${ }^{a}$ & $223104 \pm 60101$ & $146451 \pm 54606$ & $83812 \pm 52424$ & $59549 \pm 49634$ & $33301 \pm 36204$ & $29676 \pm 36394$ \\
\hline (2) LD PAMAM-Es ${ }^{b}$ & $179970 \pm 64910$ & $111880 \pm 59332$ & $91058 \pm 73949$ & $55692 \pm 46240$ & $46290 \pm 39019$ & $43015 \pm 41680$ \\
\hline (3) Lipofectamine-ES & $194664 \pm 62033$ & $163435 \pm 56293$ & $113506 \pm 50036$ & $117513 \pm 62957$ & $120533 \pm 71327$ & $131120 \pm 71257$ \\
\hline (4) PAMAM $^{\mathrm{a}, \mathrm{b}}$ & $200465 \pm 58021$ & $154130 \pm 60652$ & $128977 \pm 62570$ & $138480 \pm 85150$ & $160714 \pm 105618$ & $161172 \pm 92100$ \\
\hline (5) $\mathrm{PBS}^{\mathrm{a}, \mathrm{b}}$ & $184576 \pm 57799$ & $159941 \pm 78005$ & $130626 \pm 50700$ & $126370 \pm 58317$ & $111729 \pm 44760$ & $123874 \pm 62956$ \\
\hline
\end{tabular}

${ }^{a}$ Statistic significant difference between Group 1 and Group 3, Group 1 and Group 4, and Group 1 and Group 5 by Bonferroni test. ${ }^{b}$ Statistic significant difference between Group 2 and Group 3, Group 2 and Group 4, and Group 2 and Group 5 by Bonferroni test. (Injecting one dose of various medicines into the endometrial lesion in each group mouse on day 10.)

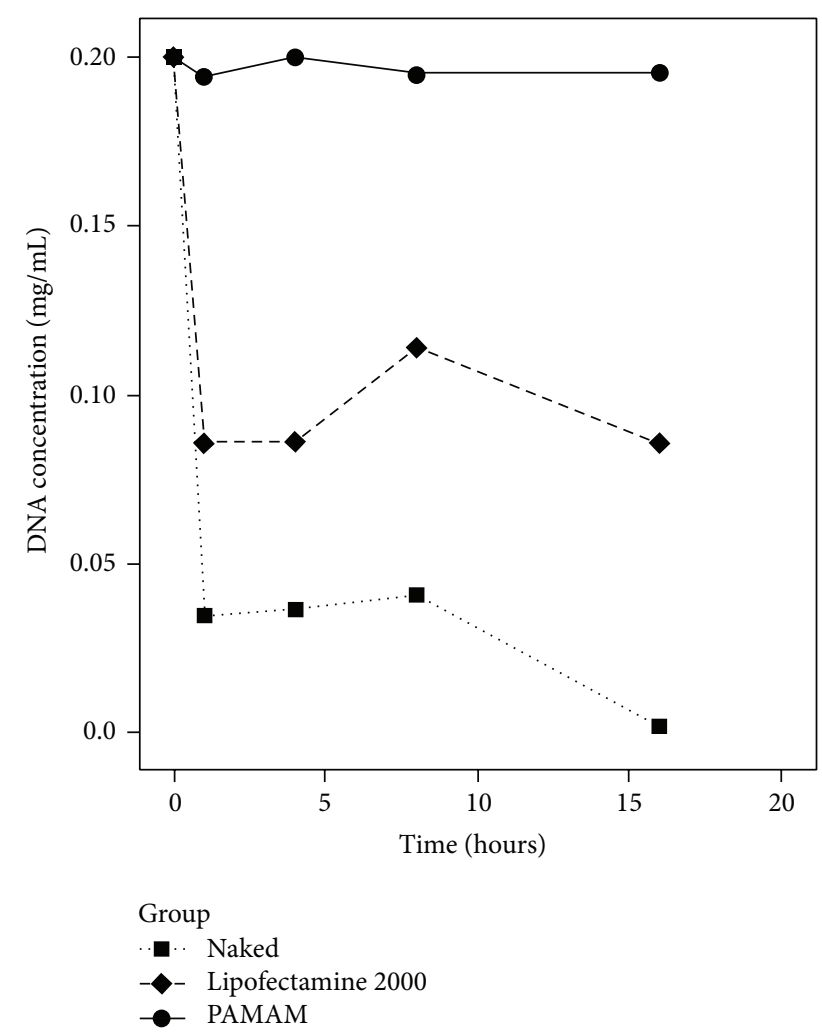

FIGURE 3: DNA concentration after digestion by DNase I (mg/mL).

TABLE 5: Lesion weight of different groups (gram, mean \pm SD).

\begin{tabular}{lc}
\hline Group & Lesion weight \\
\hline (1) HD PAMAM-Es $^{\mathrm{a}}$ & $0.0104 \pm 0.0077$ \\
(2) LD PAMAM-Es & $0.0140 \pm 0.0097$ \\
(3) Lipofectamine-Es & $0.0253 \pm 0.0158$ \\
(4) PAMAM & $0.0350 \pm 0.0245$ \\
(5) PBS $^{\mathrm{a}, \mathrm{b}}$ & $0.0378 \pm 0.0170$
\end{tabular}

$\overline{{ }^{a} \text { Statistic significant difference between Group } 1 \text { and Group } 4 \text { and Group }}$ 1 and Group 5 by Bonferroni test. ${ }^{\mathrm{b}}$ Statistic significant difference between Group 2 and Group 5.

to detect differences between groups. Two-tailed values of $P<0.05$ were considered statistically significant.
TABLE 6: Numbers of MVD (CD31-stained vessels per $\times 400$ magnification) and VEGF $H$ score (per $\times 400$ magnification) in endometriosis lesions in nude mice (mean $\pm \mathrm{SD}$ ).

\begin{tabular}{lcc}
\hline Group & MVD & VEGF H score \\
\hline (1) HD PAMAM-Es & $3.8 \pm 2.4^{\mathrm{a}}$ & $3.8 \pm 3.1$ \\
(2) LD PAMAM-Es & $10.5 \pm 3.9$ & $4.7 \pm 2.6$ \\
(3) Lipofectamine-Es & $11.4 \pm 4.7$ & $5.2 \pm 3.2$ \\
(4) PAMAM & $11.9 \pm 6.7^{\mathrm{a}}$ & $7.0 \pm 3.1$ \\
(5) PBS & $12.1 \pm 4.3^{\mathrm{a}}$ & $8.1 \pm 2.3$ \\
\hline
\end{tabular}

${ }^{\mathrm{a}}$ Statistic significant difference between Group 1 and Group 4 and Group 5.

\section{Results}

3.1. The Characteristics of ESCs and EECs in Primary Culture and after Viral Transfection. ESCs attached to the 6-well plate 12 hrs after placement began to express GFP. The intensity of fluorescence increased until $18 \mathrm{hrs}$ and was maintained at a high level (Figure 1). According to our previous result, after $18 \mathrm{hrs}$ of incubation, both ESCs and EECs had high GFP positive rates and low apoptosis rates [14]. Thus, ESCs and EECs were harvested $18 \mathrm{hrs}$ after transfection and collected to build a noninvasive animal model.

3.2. Morphology, DNA Protection Effect, and Cytotoxicity of PAMAM-Es. The morphology of PAMAM and PAMAM-Es was detected by transmission electron microscopy (Figure 2). The diameter of the PAMAM monomer ranged from 5 to $10 \mathrm{~nm}$, consistent with the description of the product $(5.4 \mathrm{~nm})$. The PAMAM monomer polymerized and formed compounds with diameters ranging from 50 to $200 \mathrm{~nm}$. No differences were found between PAMAM and PAMAM-Es in morphology under transmission electron microscopy.

In the study on the DNA protective effects, as shown in Figure 3, the DNA concentration of the PAMAM-Es mixture was much higher than the Lipofectamine-Es mixture and the naked endostatin plasmid after digestion by DNase I. After $16 \mathrm{hrs}$ of digestion, the naked plasmid had almost broken down, and the plasmid protected by Lipofectamine reduced to approximately half of the primary concentration, while DNA decreased slightly under the protection of PAMAM.

To analyze cytotoxicity in various reagents to ESCs and EECs, OD495 absorbance, representing live cell activity, was compared among each group via one-way ANOVA. As shown in Table 3, toxicity levels among 6 types of reagents to ESCs, 

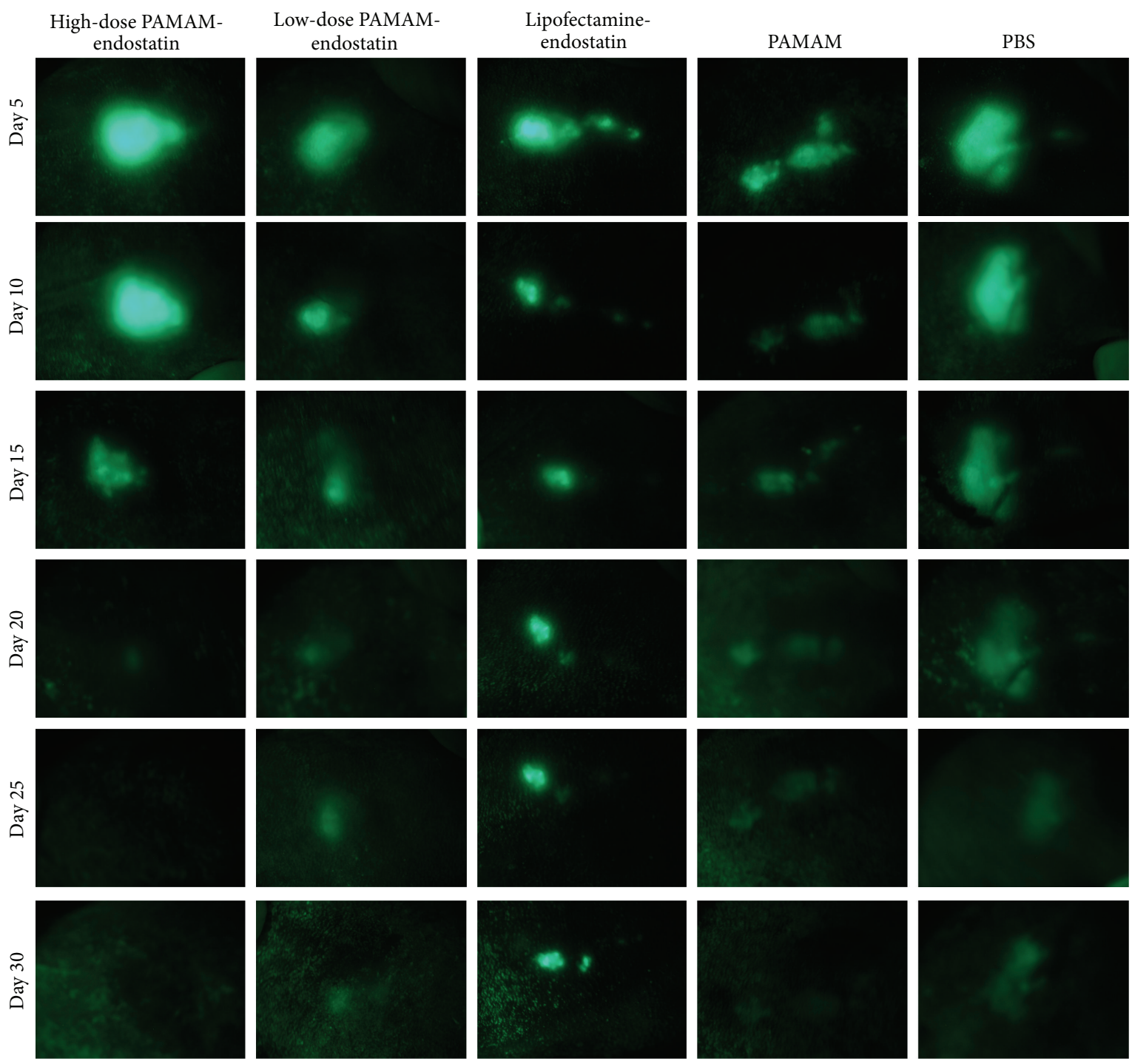

FIGURE 4: In vivo observation by fluorescent microscopy of nude mice in each group.

rather than to EECs, had statistically significant differences at both 24 and $48 \mathrm{hrs}$. The post hoc Bonferroni test showed that, when compared with the control group, high concentrations of PAMAM-Es, Lipo-Es, and PAMAM groups significantly inhibited the activity and growth of ESCs, while the inhibition of ESCs with moderate concentrations of PAMAM-Es and low concentrations of PAMAM-Es groups was not significant and demonstrated a better stromal cells protective.

3.3. In Vivo Observation and Therapeutic Effects of PAMAMEndostatin. Using fluorescent microscopy, positive lesions on the models are easily detected (Figure 4). All fluorescent images were quantitatively analyzed. To identify the fluorescent area in the photos, we studied the corelationship between the fluorescent area in the image and the volume of the same lesion, as measured by the vernier caliper and calculated with a formula. The correlation test illustrated that, when combining data from five groups, there is a statistically significant positive correlation between the fluorescent pixel numbers and the lesion volumes (Figure 5, with a $R=0.590$ and $P<0.001)$. This result demonstrated that the fluorescent area was representative of the lesion size in the noninvasive in vivo study. Therefore, we used the quantitatively analyzed fluorescent area to study the therapeutic effects of PAMAMEs on endometriosis.

First, to evaluate the homogeneity of pretreatment states among groups, lesion volumes and fluorescent areas on days 5 and 10 were compared by one-way ANOVA. The results showed that no significant differences existed between the lesion volumes and the fluorescent areas among groups.

Then, we compared the inhibition of PAMAM-Es to endometriotic lesions with Lipofectamine-Es, PAMAM, and PBS controls. Two-way ANOVA tests showed that there was a statistically significant difference among the groups (Table 4). The post hoc Bonferroni test demonstrated that high-dose and low-dose PAMAM-Es reduced the size of the lesions compared with other reagent groups. 


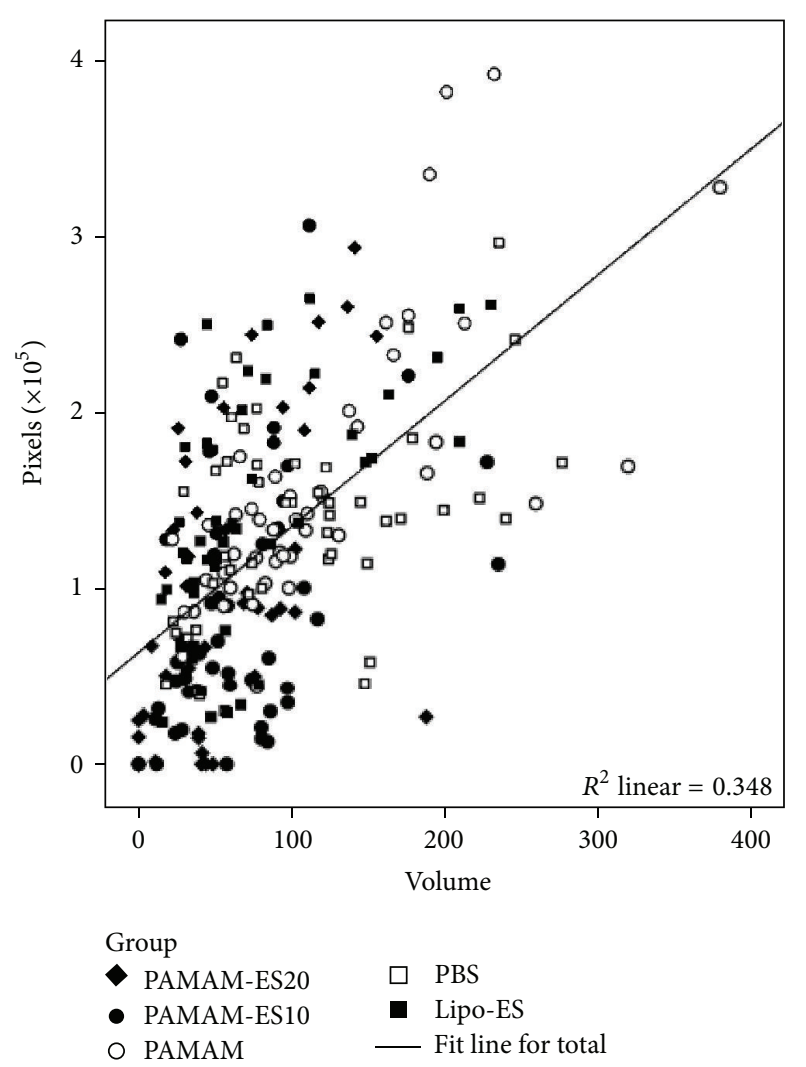

FIGURE 5: Correlation between fluorescent pixel number and lesion volume.

After 30 days of noninvasive observation, mice were sacrificed and the lesions were collected (Figure 6) and weighed. The one-way ANOVA test showed that the tumor burden among each group had a statistically significant difference. In the post hoc Bonferroni test, the HD PAMAM-Es group had a statistically significant lower lesion weight than PAMAM and PBS controls and the LD PAMAM-Es group had a statistically significant lower lesion weight than PBS controls (Table 5).

3.4. Evaluation of the Antiangiogenesis Efficiency of PAMAMEs. To investigate whether PAMAM-Es inhibited endometriotic lesions through an antiangiogenesis mechanism, two well-recognized angiogenesis biomarkers, CD31 and VEGF, were detected by immunohistochemistry (Figure 7) on every lesion and compared among the groups. There was a statistically significant difference in MVD, calculated as CD31stained vessels per $\times 400$ magnification, among the 5 groups in the ANOVA test $(P=0.023)$. HD PAMAM-Es group showed a greater antiangiogenesis effect than both the PAMAM and PBS groups in the post hoc Bonferroni test (Table 6). The ANOVA test found no difference in the VEGF $H$ score among the 5 groups $(P=0.092)$ (Table 6 ).

\section{Discussion}

Although several approaches can be applied, there is no ideal therapy method for endometriosis. Hormonal treatment has substantial side effects, whereas it does not remove the ectopic lesion radically. Conservative surgery can excise the ectopic lesion, but the disease recurs in part of patients. Radical surgery can directly affect reproducibility. Thus, new methods should be investigated to treat endometriosis [19]. Considering the characteristic of endometriosis, an ideal reagent should have followed these features: (1) reducing or removing the ectopic lesion; (2) reducing side effects, especially to the reproductive system; (3) preventing recurrence.

Endostatin is considered the most effective inhibitor of microvessel growth [1] and has been used to treat endometriosis [1,7-11, 20,21]. Our previous results [12] showed that $20 \mu \mathrm{g}$ Lipofectamine mediated endostatin for lesion injection could significantly reduce the volume of the ectopic lesion by destroying established vessels after 21 days treatment or inhibiting angiogenesis factor-VEGF mRNA at day 3 treatment in the lesion. However, the effect of Lipofectamine mediated endostatin can last a period but still existed ESCs inhibited potentially. Common lesions in nude mice should wait near 28 days enough to form a $4 \mathrm{~mm}$ diameter lesion to observe the treatment result. To resolve this problem, we attempted to change noninvasive model and more effective vector in the experiment treatment.

The green fluorescent human endometriosis lesion model which was supported on isolation-transfection-incubation procedure by injecting GFP-Adenovirus transfected human ESCs and EECs subcutaneously into nude mice was continued to be used for noninvasively evaluating the effect of various treatments [14]. Except for high transfection rate and low apoptosis rate, there were several other advantages. First, GFP labeling enabled us to repeatedly observe the lesion in a noninvasive manner; thus, changes in lesions after treatment could be detected directly rather than from necropsy, and continuous data rather than endpoint information could be more accurately analyzed. Second, injection of separated cells rather than a whole tissue increased the reliability of the results. Researchers usually implanted whole pieces of transfected and nontransfected endometrium to build an endometriosis model. In these cases, although the same pieces of tissue were used in each host animal, the exact number of cells injected was unknown. However, in our study, the number of injected cells was controlled and the baseline of each host mouse was the same.

To the best of our knowledge, it was the first study applying polyamidoamine (PAMAM) dendrimers as a gene vector in the antiangiogenesis therapy of endometriosis. We primarily tested the cytotoxicity of the PAMAM-Es compound on ESCs and EECs in vitro. CCK-8 studies demonstrated that stromal cells were sensitive to high concentrations (HC) of PAMAM-Es, PAMAM, and Lipofectamine 2000Es but not by moderate (MC) or low concentrations (LC) of PAMAM-Es demonstrating such that MC PAMAM-Es and LC PAMAM-Es reagent could be more safely used for treatment than Lipofectamine 2000 that we have used before. On the DNA protective effects, DNA decreased slightly under the protection of PAMAM. On the basis of in vitro experiment, the dose of endostatin used in the MC PAMAMEs group was $0.00001 \mu \mathrm{g}$ per stromal cell in vitro, which is calculated to be applied with HD PAMAM-Es group $(20 \mu \mathrm{g}$ 

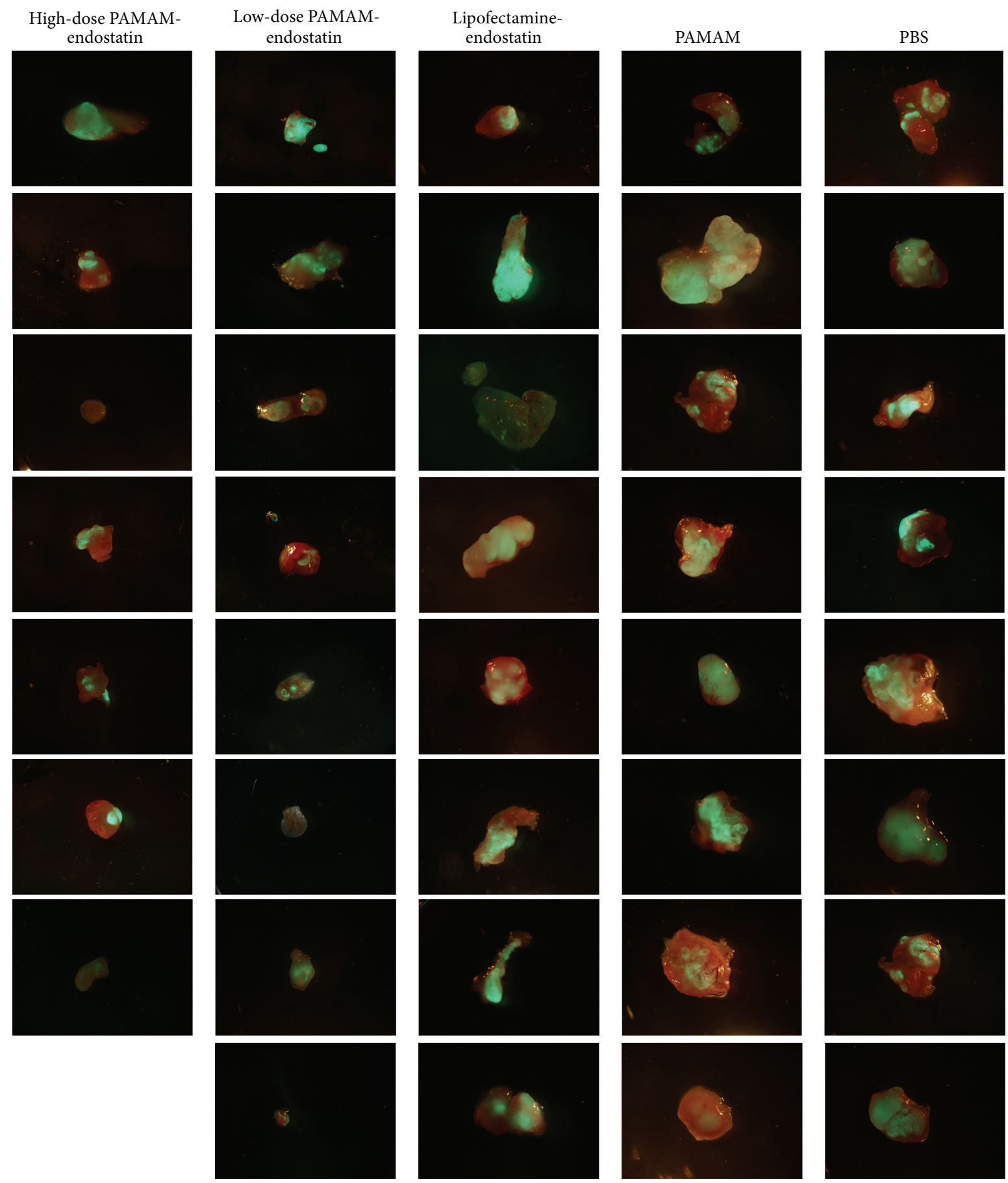

FIGURE 6: Fluorescent lesions observed after necropsy (combined by fluorescent imaging and white light picture).

$\mathrm{Es} / 2 * 10^{6} \mathrm{ESCs}$ ) in vivo. In vivo noninvasive observations in the nude mice model illustrated that PAMAM-Es with a dosedependent effect had been more effective on inhibiting the growth of endometriotic lesions and avoiding ESCs affected than the Lipofectamine Es.

To uncover whether PAMAM-Es inhibited the growth of endometriotic lesions because of its antiangiogenesis effect, we employed the fluorescent pixel number which was positive correlation to lesion volume and the immunohistochemistry to detect the microvessel density of the lesion. The results demonstrated further that $20 \mu \mathrm{g}$ PAMAM-Es significantly directly reduced the microvessel density leading to a decrease in fluorescent pixel number. These noninvasive observing results support our previous research not only on the endostatin gene therapy but also on PAMAM mediated for the management of endometriosis. There are primarily two strategies for antiangiogenesis therapy. One is to prevent angiogenesis in the newly developing lesion; the other is to 


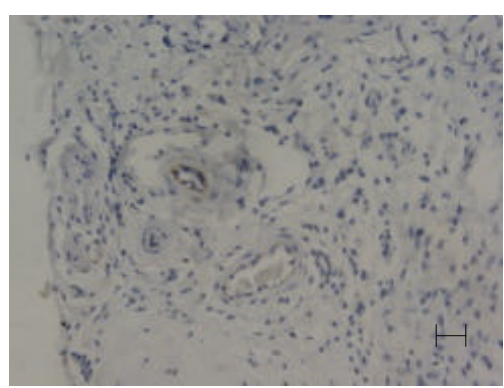

(a)

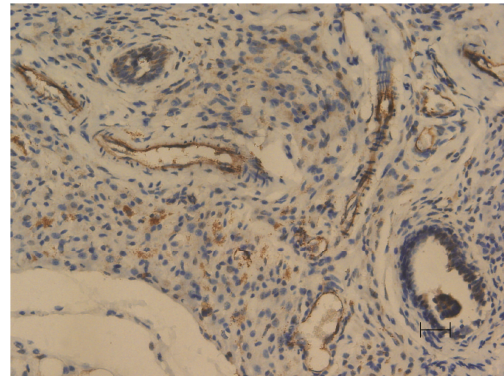

(c)

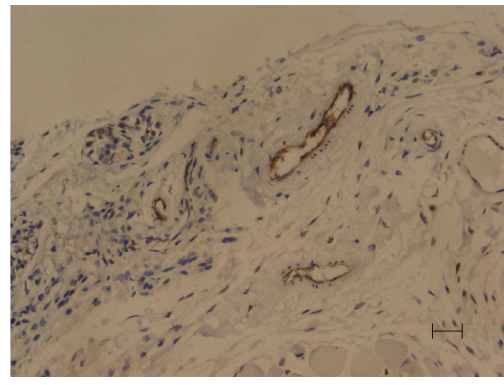

(e)

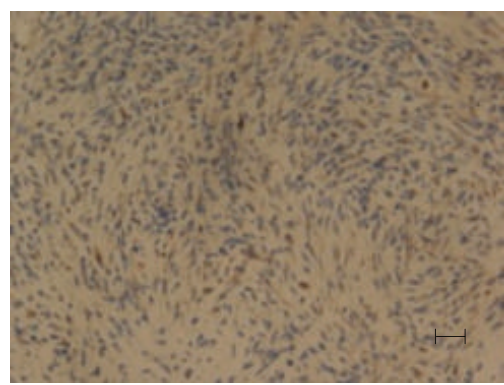

(g)

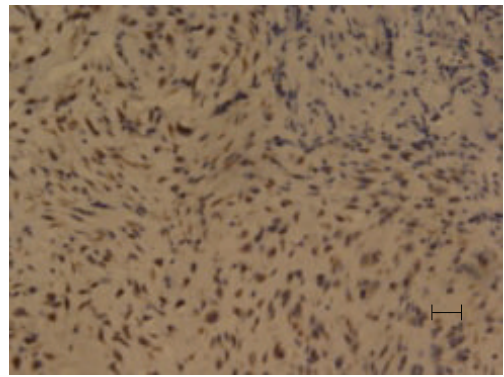

(i)

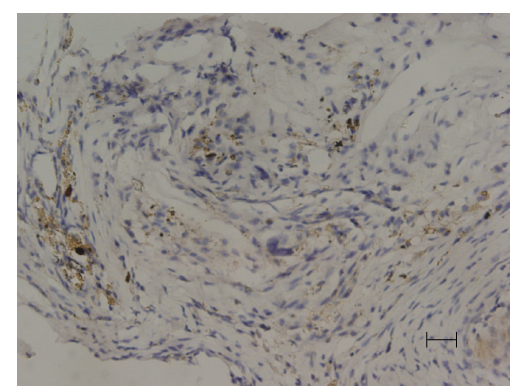

(b)

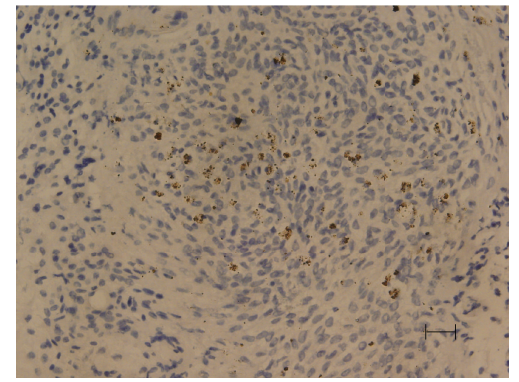

(d)

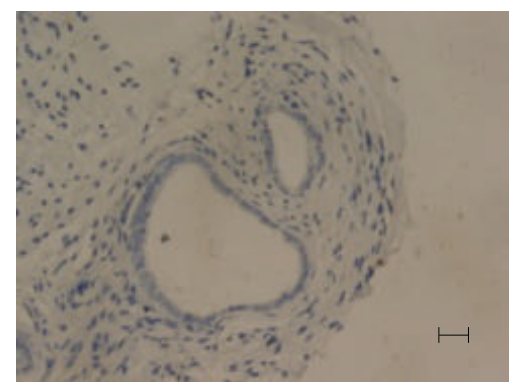

(f)

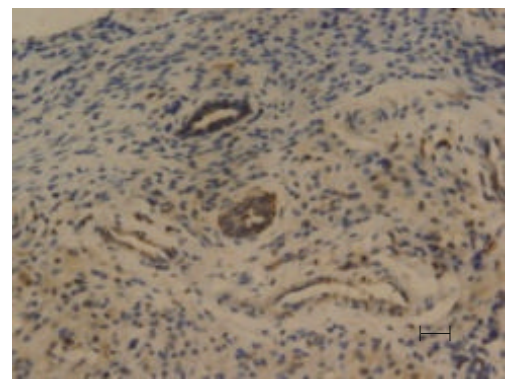

(h)

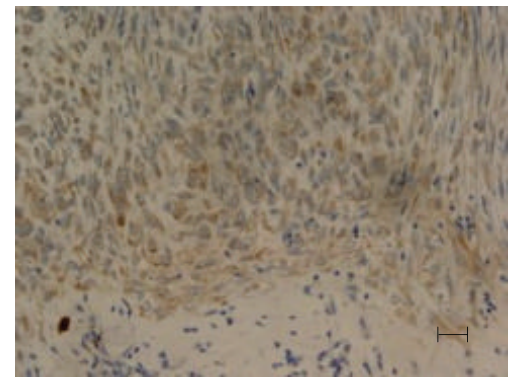

(j)

FIGURE 7: CD31 and VEGF expression in endometrial lesions in nude mice (400x, Bar $=100 \mu \mathrm{m})(\mathrm{a}-\mathrm{e})$ : CD31 expression in microvessels in the implanting lesions ((a) HD Pamam-Es; (b) LD PAMAM-Es; (c) Lipofectamine-Es; (d) PAMAM; (e) PBS); (f-j): VEGF expression in cells of the implanting lesions ((f) HD Pamam-Es; (g) LD PAMAM-Es; (h) Lipofectamine-Es; (i) PAMAM; (j) PBS). 
inhibit vascular growth in the established lesion. Therefore, in experimental endometriosis, antiangiogenesis reagents were used before or at the time of transplantation as preventive measures or after lesion formation as treatment. Eggermont et al. demonstrated that newly developing vessels were usually established between 5 and 8 days after graft implantation [22]. Thus, our data suggested that, after transduction and expression, endostatin could also inhibit established vessels in the endometriotic lesion after 10 days implantation.

Further, VEGF is considered a pivotal angiogenic factor by inducing endothelial cell-specific mitogenic and vascular permeability activities [20, 23]. Immunostaining showed that PAMAM-Es did not induce a reduction directly in VEGF expression after 20 days treatment as same as the lipofectamine Es but short effect should be confirmed in the future experiment.

In summary, compared with the traditional gene carrier Lipofectamine in vitro and in vivo, study in the present research demonstrates that PAMAM is an ideal vector in gene therapy for the treatment of endometriosis. Endostatinloaded PAMAM inhibits the development of endometriosis through an antiangiogenic mechanism and can be observed through the green fluorescent endometriosis model.

\section{Conclusions}

Endostatin-loaded PAMAM inhibits the development of endometriosis through an antiangiogenic mechanism and can be observed through the noninvasive endometriosis model.

\section{Disclosure}

Ningning Wang and Bin Liu are cofirst authors.

\section{Conflict of Interests}

The authors declare that there is no conflict of interests regarding the publication of this paper.

\section{Acknowledgments}

The authors thank Professor Guanglun Zhuang from Reproductive Center of the First Affiliated Hospital of Sun Yatsen University, Associate Professor Zhang Jin-xin from the College of Public Health of Sun Yat-sen University and Professor Yihai Cao from Department of Microbiology, Tumor and Cell Biology (MTC) at Karolinska Institutet for their guidance. The authors also thank Professor Andy Peng Xiang from the Stem Cell and Tissue Engineering Center of Sun Yat-sen University and Professor Canquan Zhou from Reproductive Center of the First Affiliated Hospital of Sun Yat-sen University for their support. This research was continuously cofunded by the National Natural Science Foundation (no. 81170550 and no. 30762222), the Foundation for Science and Technology of Guangzhou Municipality (no. 2010Y-C011), and the Science and Technology Planning Project of Guangdong Province (no. 2010B050700009).

\section{References}

[1] A. W. Nap, A. W. Griffioen, G. A. Dunselman et al., "Antiangiogenesis therapy for endometriosis," Journal of Clinical Endocrinology and Metabolism, vol. 89, no. 3, pp. 1089-1095, 2004.

[2] J. A. Sampson, "Peritoneal endometriosis due to the menstrual dissemination of endometrial tissue into the peritoneal cavity," American Journal of Obstetrics and Gynecology, vol. 14, pp. 422469, 1927.

[3] C. A. M. Koks, P. G. Groothuis, G. A. J. Dunselman, A. F. P. M. de Gocij, and J. L. H. Evers, "Adhesion of shed menstrual tissue in an in-vitro model using amnion and peritoneum: a light and electron microscopic study," Human Reproduction, vol. 14, no. 3, pp. 816-822, 1999.

[4] J. W. M. Maas, P. G. Groothuis, G. A. J. Dunselman, A. F. P. M. de Goeij, H. A. J. Struijker-Boudier, and J. L. H. Evers, "Development of endometriosis-like lesions after transplantation of human endometrial fragments onto the chick embryo chorioallantoic membrane," Human Reproduction, vol. 16, no. 4, pp. 627-631, 2001.

[5] J. W. M. Maas, P. G. Groothuis, G. A. J. Dunselman, A. F. P. M. de Goeij, H. A. J. Struyker Boudier, and J. L. H. Evers, "Endometrial angiogenesis throughout the human menstrual cycle," Human Reproduction, vol. 16, no. 8, pp. 1557-1561, 2001.

[6] M. Nisolle, F. Casanas-Roux, V. Anaf, J. M. Mine, and J. Donnez, "Morphometric study of the stromal vascularization in peritoneal endometriosis," Fertility and Sterility, vol. 59, no. 3, pp. 681-684, 1993.

[7] C. M. Becker, D. A. Sampson, M. A. Rupnick et al., "Endostatin inhibits the growth of endometriotic lesions but does not affect fertility," Fertility and Sterility, vol. 84, no. 2, pp. 1144-1155, 2005.

[8] H.-Q. Jiang, Y.-L. Li, and J. Zou, "Effect of recombinant human endostatin on endometriosis in mice," Chinese Medical Journal, vol. 120, no. 14, pp. 1241-1246, 2007.

[9] C. M. Becker, D. A. Sampson, S. M. Short, K. Javaherian, J. Folkman, and R. J. D'Amato, "Short synthetic endostatin peptides inhibit endothelial migration in vitro and endometriosis in a mouse model," Fertility and Sterility, vol. 85, no. 1, pp. 71-77, 2006.

[10] C. M. Becker, R. D. Wright, R. Satchi-Fainaro et al., "A novel noninvasive model of endometriosis for monitoring the efficacy of antiangiogenic therapy," The American Journal of Pathology, vol. 168, no. 6, pp. 2074-2084, 2006.

[11] A. W. Nap, G. A. J. Dunselman, A. W. Griffioen, K. H. Mayo, J. L. Evers, and P. G. Groothuis, "Angiostatic agents prevent the development of endometriosis-like lesions in the chicken chorioallantoic membrane," Fertility and Sterility, vol. 83, no. 3, pp. 793-795, 2005.

[12] N. N. Wang, J. F. Tan, and H. J. Ding, "Effect of lipofectaminemediated endostatin gene therapy on human endometriosis lesions in nude mice," Medical Journal of Chinese People's Liberation Army, vol. 34, no. 12, pp. 1430-1433, 2009.

[13] A. Shakhbazau, I. Isayenka, N. Kartel et al., "Transfection efficiencies of PAMAM dendrimers correlate inversely with their hydrophobicity," International Journal of Pharmaceutics, vol. 383, no. 1-2, pp. 228-235, 2010.

[14] B. Liu, N. N. Wang, and Z. L. Wang, "Improved nude mouse models for green fluorescence human endometriosis," Journal of Obstetrics and Gynaecology Research, vol. 36, pp. 1214-1221, 2010. 
[15] I. P. Ryan, E. D. Schriock, and R. N. Taylor, "Isolation, characterization, and comparison of human endometrial and endometriosis cells in vitro," The Journal of Clinical Endocrinology and Metabolism, vol. 78, no. 3, pp. 642-649, 1994.

[16] M. Fortin, M. Lépine, Y. Merlen et al., "Quantitative assessment of human endometriotic tissue maintenance and regression in a noninvasive mouse model of endometriosis," Molecular Therapy, vol. 9, no. 4, pp. 540-547, 2004.

[17] N. Weidner, "Intratumor microvessel density as a prognostic factor in cancer," The American Journal of Pathology, vol. 147, no. 1, pp. 9-19, 1995.

[18] J. Donnez, P. Smoes, S. Gillerot, F. Casanas-Roux, and M. Nisolle, "Vascular endothelial growth factor (VEGF) in endometriosis," Human Reproduction, vol. 13, no. 6, pp. 1686-1690, 1998.

[19] S. Ferrero, L. H. Abbamonte, P. Anserini, V. Remorgida, and N. Ragni, "Future perspectives in the medical treatment of endometriosis," Obstetrical and Gynecological Survey, vol. 60, no. 12, pp. 817-826, 2005.

[20] J. G. Kim, J. Y. Kim, B. C. Jee, C. S. Suh, S. H. Kim, and Y. M. Choi, "Association between endometriosis and polymorphisms in endostatin and vascular endothelial growth factor and their serum levels in Korean women," Fertility and Sterility, vol. 89, no. 1, pp. 243-245, 2008.

[21] D. E. Machado, P. T. Berardo, C. Y. Palmero, and L. E. Nasciutti, "Higher expression of vascular endothelial growth factor (VEGF) and its receptor VEGFR-2 (Flk-1) and metalloproteinase-9 (MMP-9) in a rat model of peritoneal endometriosis is similar to cancer diseases," Journal of Experimental and Clinical Cancer Research, vol. 29, no. 1, article 4, 2010.

[22] J. Eggermont, J. Donnez, F. Casanas-Roux, H. Scholtes, and A. van Langendonckt, "Time course of pelvic endometriotic lesion revascularization in a nude mouse model," Fertility and Sterility, vol. 84, no. 2, pp. 492-499, 2005.

[23] N. Yamaguchi, B. Anand-Apte, M. Lee et al., "Endostatin inhibits VEGF-induced endothelial cell migration and tumor growth independently of zinc binding," The EMBO Journal, vol. 18, no. 16, pp. 4414-4423, 1999. 


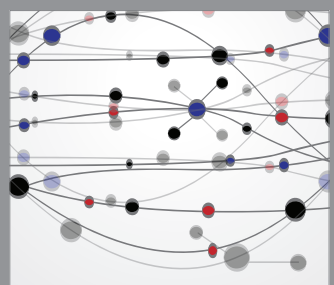

The Scientific World Journal
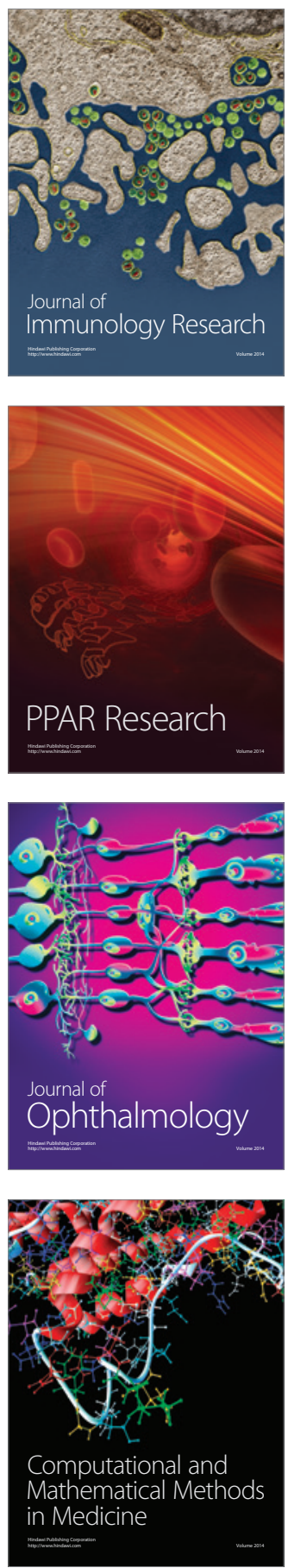

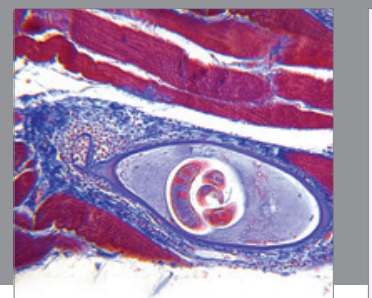

Gastroenterology

Research and Practice
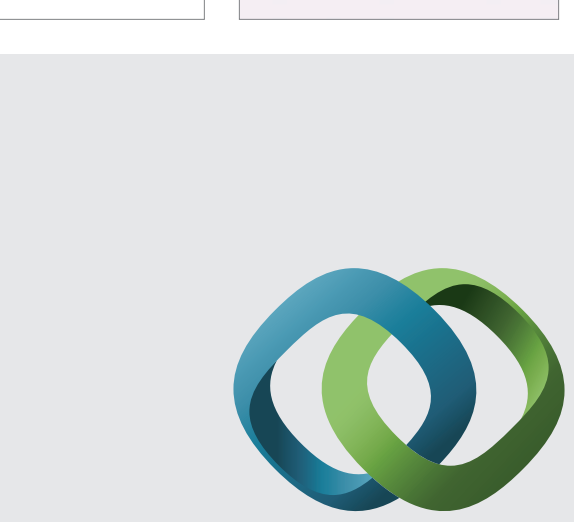

\section{Hindawi}

Submit your manuscripts at

http://www.hindawi.com
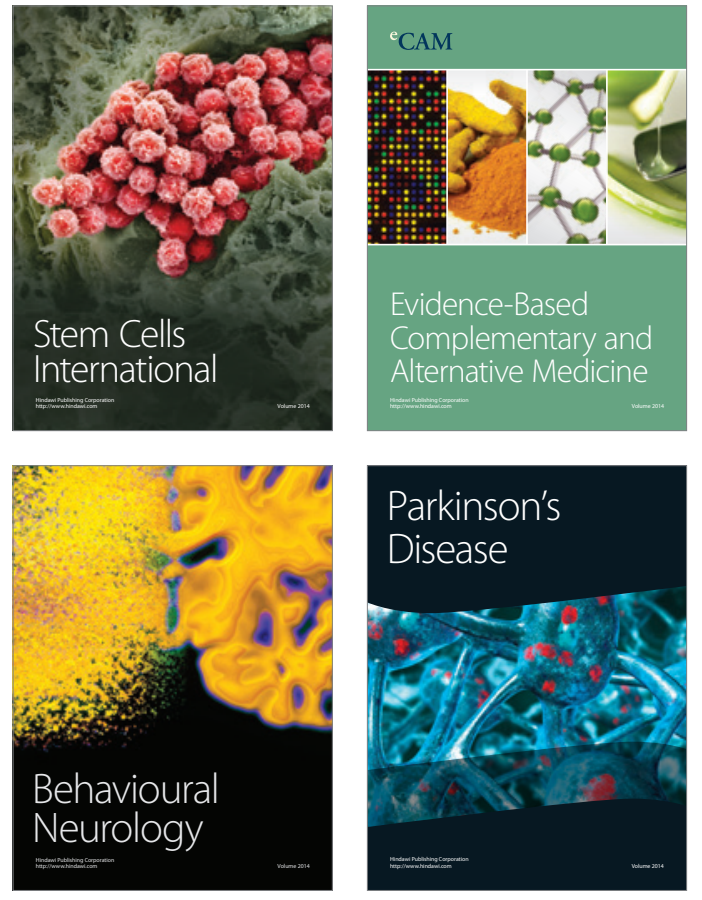
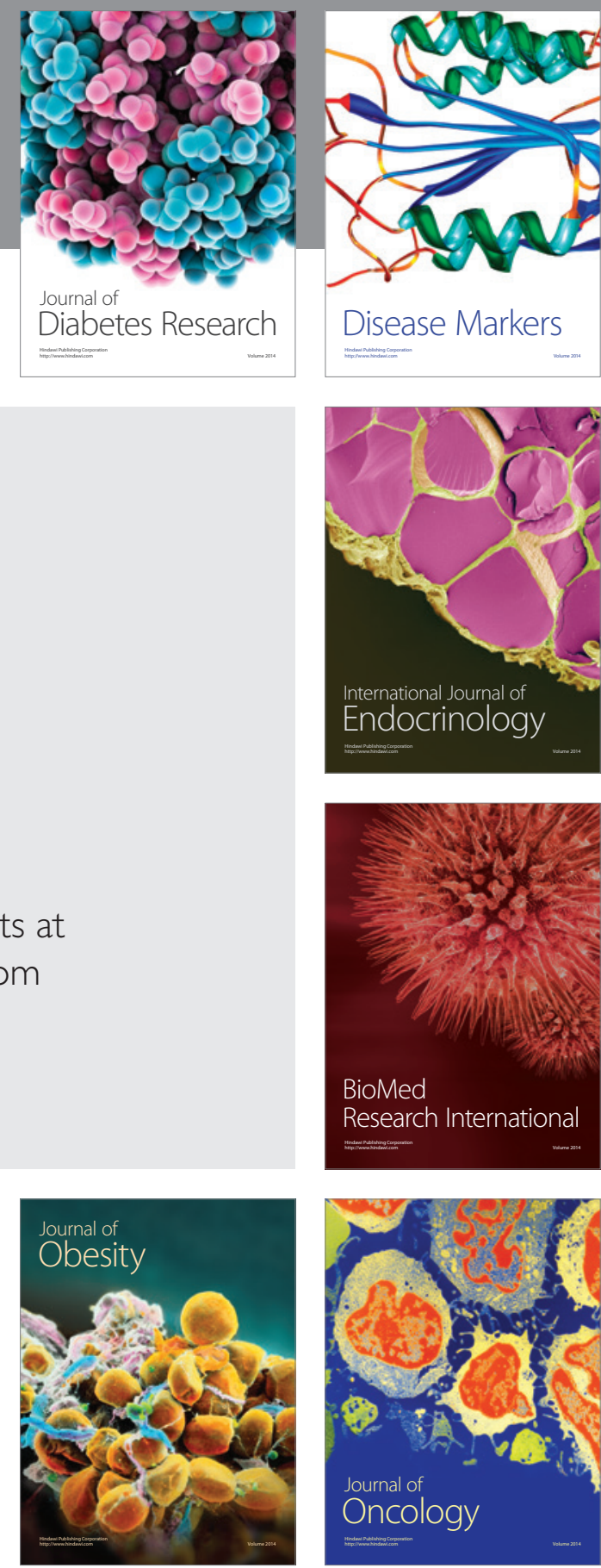

Disease Markers
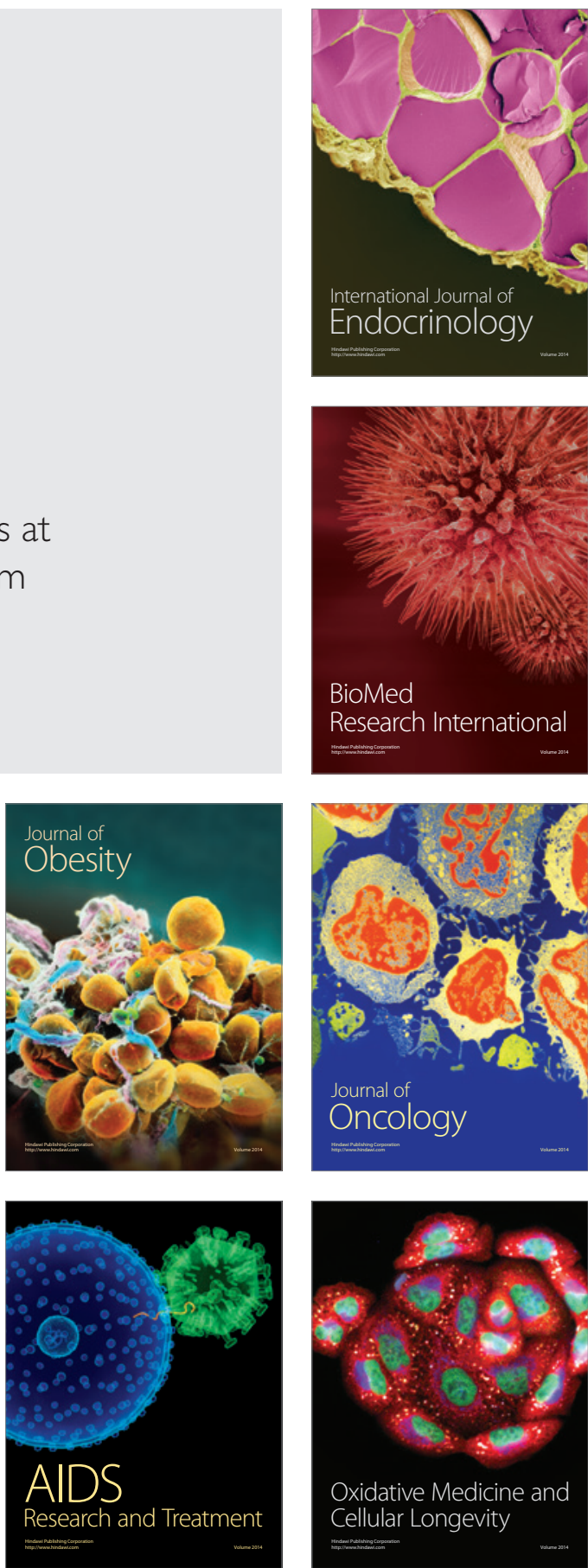